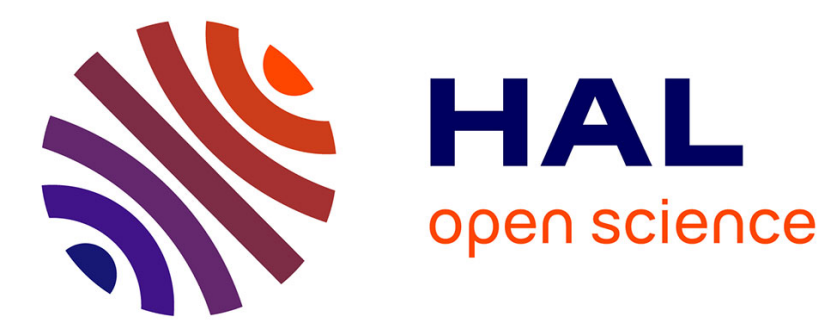

\title{
Optical spectroscopy of Eu3+ ion as a tool for the study of dehydration process in silica gels
}

\author{
A. Piazza, Adel Bouajaj, M. Ferrari, M. Montagna, R. Campostrini, G. \\ Carturan
}

\section{- To cite this version:}

A. Piazza, Adel Bouajaj, M. Ferrari, M. Montagna, R. Campostrini, et al.. Optical spectroscopy of Eu3+ ion as a tool for the study of dehydration process in silica gels. Journal de Physique IV Proceedings, 1994, 04 (C4), pp.C4-569-C4-572. 10.1051/jp4:19944137 . jpa-00252589

\section{HAL Id: jpa-00252589 https://hal.science/jpa-00252589}

Submitted on 1 Jan 1994

HAL is a multi-disciplinary open access archive for the deposit and dissemination of scientific research documents, whether they are published or not. The documents may come from teaching and research institutions in France or abroad, or from public or private research centers.
L'archive ouverte pluridisciplinaire HAL, est destinée au dépôt et à la diffusion de documents scientifiques de niveau recherche, publiés ou non, émanant des établissements d'enseignement et de recherche français ou étrangers, des laboratoires publics ou privés. 


\title{
Optical spectroscopy of $\mathrm{Eu}^{3+}$ ion as a tool for the study of dehydration process in silica gels
}

\author{
A. PIAZZA* A. BOUAJAJ ${ }^{*}(1)$, M. FERRARI*, M. MONTAGNA**, R. CAMPOSTRINI ${ }^{* * *}$ and \\ G. CARTURAN ${ }^{* * *}$ \\ ${ }^{*}$ CNR, Centro di Fisica degli Stati Aggregati ed Impianto Ionico, via Sommarive 14, 38050 Povo (TN), \\ Italy \\ ** Dipartimento di Fisica, Università di Trento, via Sommarive 14, 38050 Povo (TN), Italy \\ ${ }^{* * *}$ Dipartimento di Ingegneria dei Materiali, Università di Trento, 38050 Mesiano (TN), Italy
}

\begin{abstract}
The structural modification induced by dehydration in optical silica gel has been studied using the spectroscopy of $\mathrm{Eu}^{3+}$ ion. The samples, doped with molar ratio $\mathrm{Eu} / \mathrm{Si}=0.01: 1$, were heated for 48 hours at different temperatures from $60{ }^{\circ} \mathrm{C}$ to $200{ }^{\circ} \mathrm{C}$. Information on the dinamical properties of the local environment of the $\mathrm{Eu}^{3+}$ were obtained both by fluorescence and excitation measurements at $\mathrm{T}=11 \mathrm{~K}$. The analysis of the ${ }^{5} \mathrm{D}_{0} \rightarrow{ }^{7} \mathrm{~F}_{0}$ transition appears of particular relevance in this study, because the transition is between $J=0$ states and does not present internal structure. Its inhomogeneous linewidth gives a measure of the energy distribution of the different $\mathrm{Eu}^{3+}$ sites. Site selection spectroscopy was performed by exciting into the ${ }^{5} \mathrm{D}_{1}$ state. Three different sets of sites were found. The phonon sidebands of the ${ }^{5} D_{0} \leftarrow F_{0}$ and ${ }^{5} D_{1} \leftarrow{ }^{7} F_{0}$ transitions were observed in the excitation spectra.
\end{abstract}

\section{Introduction}

Rare earth doped optical silica sol-gel are of great interest in the field of technological applications [1]. The structural and dynamical modifications induced by the densification process becomes important for controlling the final properties of the system. At this aim the early stage of gel $\rightarrow$ xerogel transition is quite determinant. Indeed it is at this step of the growth that the original structure and morphology of the xerogel will be determined. In this work we study samples of acid-catalyzed silica gel in this zone of dehydration. For this purpose we use the powerful tool of the spectroscopical properties of the $\mathrm{Eu}^{3+}$ ion [2]. We focus us on the vibronic sideband of the ${ }^{5} \mathrm{D}_{0} \leftarrow{ }^{7} \mathrm{~F}_{0}$ and ${ }^{5} \mathrm{D}_{1} \leftarrow{ }^{7} \mathrm{~F}_{0}$ transitions and on the site selection by excitation in the ${ }^{5} \mathrm{D}_{1}$ state.

\section{Experimental}

The samples were obtained by hydrolysis and copolymerization of dietoxydimethylsilane (DEDMS) and tetraethoxysilane (TEOS) as described in a previous work [3]. The gels used in this study were doped with a molar ratio $\mathrm{Eu} / \mathrm{Si}=0.01 / 1$ The heat treatments, reported in $\mathrm{Tab}$. I, were performed in air for 48 hours at different temperatures in the range $60-200^{\circ} \mathrm{C}$.

(1) Permanent address: Physico-Chimie des Matériaux Luminescents, URA 172 du CNRS, Université Lyon I, 43 bd du 11 Novembre 1918, 69622 Villeurbanne, France 


\begin{tabular}{|c|c|c|c|c|c|c|c|c|c|}
\hline Gel & G1 & G2 & G3 & G4 & G5 & G6 & G7 & G8 & G9 \\
\hline T $\left({ }^{\circ} \mathrm{C}\right)$ & NONE & 60 & 80 & 100 & 120 & 140 & 160 & 180 & 200 \\
\hline
\end{tabular}

Table I: Sample labelling according to the temperatures of the heat treatments.

Pulsed excitation was performed by a dye laser with Rh6G or with a mixing of Coumarin 153 and Coumarin 307, pumped by an excimer laser at $308 \mathrm{~nm}$. Fluorescence and excitation spectra were recorded in time resolved spectroscopy.

\section{Results and Discussion}

Figure 1 shows the low temperature excitation spectra, in the ${ }^{5} \mathrm{D}_{0} \leftarrow{ }^{7} \mathrm{~F}_{0}$ region, for different samples. The measurements were performed by detecting the fluorescence at $16200 \mathrm{~cm}^{-1}$ on the maximum of the ${ }^{5} \mathrm{D}_{0} \rightarrow{ }^{7} \mathrm{~F}_{2}$ transition. Note the evolution of the ${ }^{5} \mathrm{D}_{0} \leftarrow{ }^{7} \mathrm{~F}_{0}$ zero-phonon line. The inhomogeneous linewidth passes from $20 \mathrm{~cm}^{-1}$ for the wet gel (Fig. 1, G1) to $50 \mathrm{~cm}^{-1}$ for the dried gel (Fig. 1,G9). Moreover, the densification process, induces a shift of the line towards higher energies. The baricenter is at $17260 \mathrm{~cm}^{-1}$ for the wet gel and at $17295 \mathrm{~cm}^{-1}$ for the G9 sample. At intermediate heat treatments (Fig. 1, G4, G5) another component appears in the high energy region, whose intensity increases with the heat treatments. The peak at lower energy is assigned to a liquidlike environment, and the highenergy one to a dry environment [4]. A weak band appears at about $200 \mathrm{~cm}^{-1}$ from the zero-

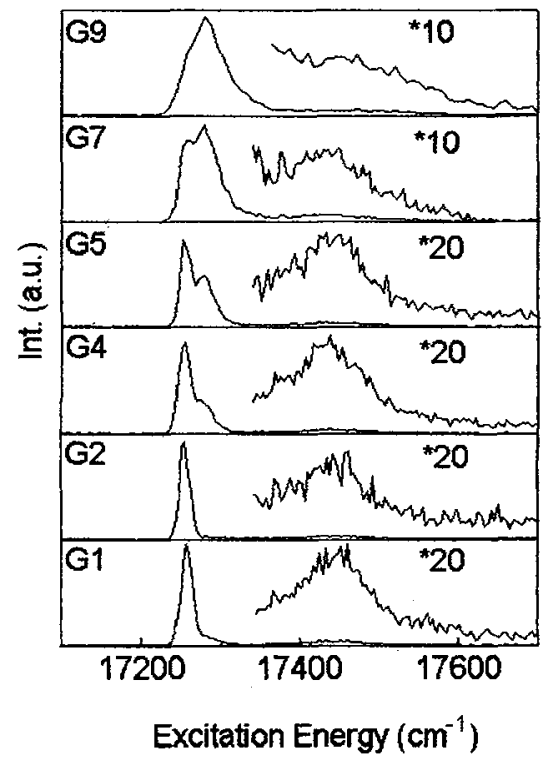

Figure1:Excitation spectra in the ${ }^{5} D_{0} \leftarrow{ }^{7} F_{a}$ region at $T=11 \mathrm{~K}$. phonon line. It seems reasonable to assign this sideband to the vibrational modes of the Europium ion with oxygen ligands. Vibronic sidebands were observed in $\mathrm{ScBO}_{3}: \mathrm{Eu}^{3+}$ crystal [5] and in sodium borate [6] and sodium silicate [7] glasses. In scandium borate [5] vibrational structures at 200 and $270 \mathrm{~cm}^{-1}$ due 
to $\mathrm{Eu}^{3 *} \leftrightarrow \mathrm{O}^{2-}$ were observed. The sideband, which is rather weak in the wet gel, becomes more intense in the dried samples. The coordination number $(\mathrm{CN})$ with water does not change very much during the drying process: a rough estimation, based on lifetime measurements, gives $\mathrm{CN}=7.5$ for the wet $\mathrm{G1}$ sample and $\mathrm{CN}=6.9$ for the intermediate G5 sample [8]. These values

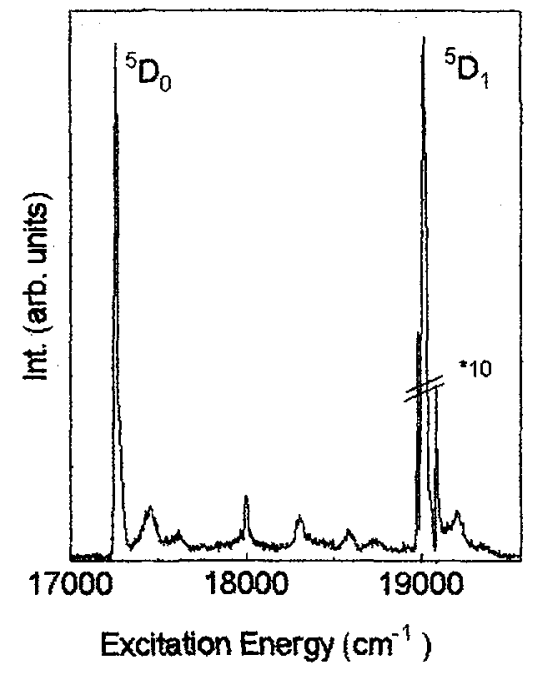

Figure 2: Excitation spectrum of the 64 sample at $T=11 K$. Rivelation energy was at $16200 \mathrm{~cm}^{-1}$ on the ${ }^{3} \mathrm{D}_{0} \rightarrow{ }^{7} \mathrm{~F}_{2}$ transition. should be compared with those obtained by X-ray diffraction studies of aqueous rare earth solutions where the average $\mathrm{Eu}^{3+}-\mathrm{H}_{2} \mathrm{O}$ distance is $2.450 \AA$ and the average $\mathrm{CN}$ is 8.3 [9]. Europium in the wet gel feels a relatively symmetric crystal field and the ion interacts weakly with the silica network. For these reasons a weak covalence can be expected. In a dry environment it is still possible to have high $\mathrm{CN}$ and Eu-O binding lenghts not too different [10] from those observed in the liquid, but with stronger electron-phonon coupling. In fact, the growth of the $\mathrm{SiO}_{2}$ network and the consequent local disorder will modify the binding lenghts, as well as the magnitude of the covalent iteractions between $\mathrm{Eu}^{3+}$ and the surrounding oxygen ligands which can be bridging, non bridging or free. Figure 2 shows the low temperature excitation spectrum of the ${ }^{5} \mathrm{D}_{0} \leftarrow{ }^{7} \mathrm{~F}_{0}$ and ${ }^{5} \mathrm{D}_{0} \leftarrow^{7} \mathrm{~F}_{1}$ transitions for the G4 sample. For both transitions, the vibrational sidebands are observed at about 200 and 350 $\mathrm{cm}^{-1}$ from the electronic lines. The $350 \mathrm{~cm}^{-1}$ band can be probably assegned to a Eu↔O stretching mode where the interaction is with a non bridging oxygen of the silica chain.

The low symmetry local crystal field splits the ${ }^{5} D_{1}$ state in three components. The Stark splittings will be different from site to site as shown by fluorescence line narrowing measurements $[3,4]$. Due to this inhomogeneity it is possible to have resonance between Stark levels belonging to different sites. This is the case of Figure 3 where the fluorescence of the ${ }^{5} \mathrm{D}_{0} \rightarrow{ }^{7} \mathrm{~F}_{0}$ transition, for the G4 sample, was recorded by exciting at different energies in the ${ }^{5} D_{1}$ state. The excitation energiese were: a) 18985 , b) 19015 , c) 19025 , d) 19045 , e) 19065 , f) $19085 \mathrm{~cm}^{-1}$ respectively. When only a set of centers were excited (Fig. $3 \mathrm{a}$ and 3f) we observed only one ${ }^{5} D_{0} \rightarrow{ }^{7} F_{0}$ fluorescence line. When the excitation 
energy induced population in the Stark levels of different sites the corresponding ${ }^{5} \mathrm{D}_{0} \rightarrow{ }^{7} \mathrm{~F}_{0}$ emission lines have been observed (Fig. $3 \mathrm{~b}-\mathrm{e}$ ). It is evident that for every excitation energy we obtain luminescence from different groups of

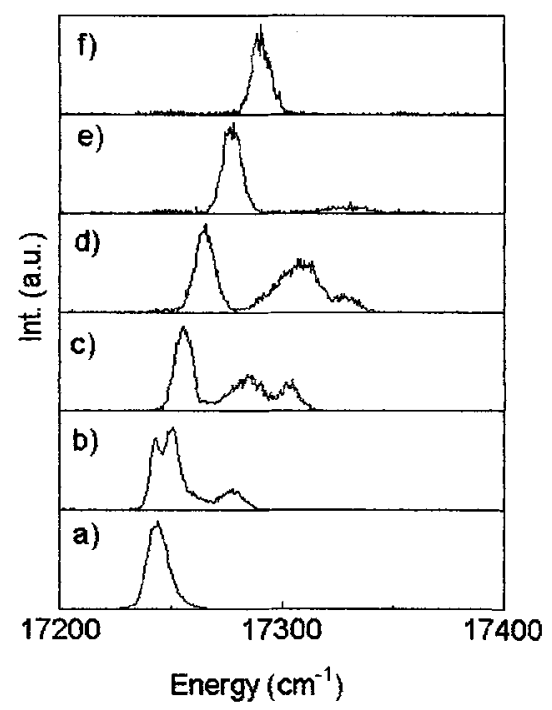
sites. In time-resolved spectra of Fig. 3 the observed lines were not disturbed by the direct ${ }^{5} \mathrm{D}_{1} \rightarrow{ }^{7} \mathrm{~F}_{3}$ emission although this falls in the same energy range, because the lifetime of the latter is a few $\mu \mathrm{s}$, while $\tau\left({ }^{5} \mathrm{D}_{0} \rightarrow{ }^{7} \mathrm{~F}_{0}\right)$ is about 200 $\mu \mathrm{s}$.

Since non resonant line narrowing of the ${ }^{5} \mathrm{D}_{0} \rightarrow{ }^{7} \mathrm{~F}_{0}$ emission line is possible by excitating in the ${ }^{5} \mathrm{D}_{1}$ state, the ionion energy transfer is negligible at this stage of the dehydration process.

Figure 3: Emission spectra of the ${ }^{5} D_{0} \rightarrow{ }^{7} F_{0}$ transition at different excitation energies (see text) into ${ }^{5} D_{1}$ state. $T=11 \mathrm{~K}$.

\section{References}

[1] R.Reisfeld and C.K.Jørgensen, Structure and Bonding, 77, 207, (1992).

[2]G.Boulon, M.Boudebala and J.Sériot, J.Less-Common Metals,112, 41, (1985).

[3] R.Campostrini, G.Carturan, M.Ferrari, M.Montagna and O.Pilla, J. Mater. Res. 7,745,(1992).

[4] M.Ferrari, A.Piazza, M.Montagna, G.Carturan and R. Campostrini, J. Sol-Gel Science and Technology, in press.

[5] G. Blasse and G.J. Dirksen, Inorg. Chim. Acta, 145, 303, (1988).

[6] S.Tanabe, S.Todoroki, K. Hirao and N. Soga, J. Non-Cryst. Solids, 122, 59, (1990).

[7] S.Todoroki, S.Tanabe, K. Hirao and N. Soga, J. Non-Cryst. Solids, 136, 213, (1991).

[8] A. Piazza, M.Montagna, M.Ferrari, G.Carturan and R. Campostrini, Proceedings of Eurogel '92, Colmar, in press.

[9] A. Habenscuss and F.H. Spedding, J. Chem. Phys. 73, 442, (1980).

[10] G.Cormier, J.A. Capobianco, C.A. Morrison, A.Monteil, Phys. Rev. B48, (1993). 